\title{
PENGARUH MODEL PEMBELAJARAN PROBLEM BASED LEARNING TERHADAP HASIL BELAJAR SISWA PADA MATERI POKOK GERAK LURUS DIKELAS X SMAN UNGGUL SUBULUSSALAM T.P 2015/2016
}

\author{
A Wahyu Kristiani N. Zebua dan Ida Wahyuni \\ Jurusan Fisika FMIPA Universitas Negeri Medan \\ Jalan Willem Iskandar Pasar V Medan, Sumatera Utara \\ wahyukristianizebua@gmail.com
}

\begin{abstract}
ABSTRAK
Penelitian ini bertujuan untuk mengetahui pengaruh model problem based learning terhadap hasil belajar siswa kelas X Semester I pada materi pokok Gerak Lurus di Kelas X SMAN Unggul Subulussalam T.P 2015/ 2016. Jenis penelitian ini adalah quasi experiment. Populasi dalam penelitian adalah seluruh siswa kelas X Semester I yang terdiri dari 3 kelas berjumlah 111 orang. Pengambilan sampel dilakukan dengan cara cluster random sampling yaitu kelas X-1 sebagai kelas eksperimen yang berjumlah 37 orang dan kelas X-2 sebagai kelas kontrol yang berjumlah 37 orang. Instrumen dalam penelitian ini ada 2 yaitu tes hasil belajar dalam bentuk essay tes dengan jumlah 10 soal dan lembar observasi untuk melihat aktivitas siswa. Melalui hasil penelitian diperoleh nilai rata-rata pretes kelas eksperimen 43,81 dan nilai rata-rata pretes kelas kontrol adalah 44,05. Berdasarkan hasil postes, diperoleh nilai rata-rata postes kelas eksperimen 80,05 dan nilai rata-rata postes kelas kontrol adalah 68,81. Rata-rata nilai keseluruhan nilai aktivitas belajar siswa adalah $72,03 \%$ termasuk dalam kategori aktif. Hasil uji $\mathrm{t}$ menunjukkan bahwa ada pengaruh yang signifikan model pembelajaran problem based learning terhadap hasil belajar siswa pada materi pokok gerak lurus di kelas X SMAN Unggul Subulussalam T.P 2015/2016.
\end{abstract}

Kata kunci : $\quad$ Model Problem Based Learning, Hasil Belajar Fisika, Gerak Lurus

\section{ABSTRACK}

This study purpose to determine the effect of problem based learning model of the learning outcomes of students of class X Semester in the subject matter Straight Motion in Class X SMAN Superior Subulussalam T.P 2015 / 2016. The research is a quasiexperiment. The population in the study were all students of class X Semester I, which consists of three classes totaling 111 people. Sampling was done by cluster random sampling is class X-1 as an experimental class numbered 37 and class X-2 as a control class that numbered 37 people. Instruments in this study there are 2 of tests of learning outcomes in the form of essay test with 10 questions and the number of pieces of observation to see student activity. The result showed the average value pretest experimental class 43.81 and the average value pretest control group was 44.05. Based on the results postes, the value of the average post-test experimental class 80.05 and the average value posttest control group was 68.81. The average value of the total value of learning activities of students is $72.03 \%$ is included in the active category. $t$ test results 
showed that there is influence learning model Problem Based Learning on learning outcomes of students in the subject matter straight motion in grade X SMAN Superior Subulussalam T.P 2015/2016.

Keywords: Model Problem Based Learning, Learning Outcomes Physics, Straight Motion 


\section{PENDAHULUAN}

Peran pendidikan sangat penting untuk menciptakan masyarakat yang cerdas, damai, terbuka dan demokratis. UU RI No. 20 Pasal 1 Tahun 2003 tentang Sistem Pendidikan Nasional telah ditetapkan bahwa "pendidikan adalah usaha sadar dan terencana untuk mewujudkan suasana belajar dan proses pembelajaran agar peserta didik secara aktif mengembangkan potensi dirinya untuk memiliki kekuatan spiritual keagamaan, pengendalian diri, kepribadian, kecerdasan, akhlak mulia, serta keterampilan yang diperlukan dirinya, masyarakat, bangsa dan negara".

Pembelajaran adalah proses interaksi antara peserta didik dengan guru dan sumber belajar pada suatu lingkungan belajar (Rusman, 2012 : 3). Tugas guru yang paling utama adalah mengkondisikan lingkungan agar menunjang terjadinya perubahan perilaku bagi peserta didik. Pembelajaran dalam Kurikulum Tingkat Satuan Pendidikan (KTSP) adalah pembelajaran dimana hasil belajar atau kompetensi yang diharapkan dicapai oleh siswa, system penyampaian, dan indikator dan pencapaian hasil belajar dirumuskan secara tertulis sejak perencanaan dimulai.

Bidang studi sains termasuk fisika sebagai bagian dari Ilmu Pengetahuan Alam (IPA) merupakan objek mata pelajaran yang menarik dan lebih banyak memerlukan pemahaman dari pada penghafalan. Kenyataannya, fisika sering dipandang sebagai suatu ilmu yang abstrak oleh siswa dengan teori dan soal-soal yang sulit. Berdasarkan pengalaman penulis saat melakukan Program Pengalaman Lapangan (PPL), bahwa dalam kegiatan belajar mengajar siswa hanya diberikan teori-teori dan cara menyelesaikan soal-soal fisika tanpa mengarahkan siswa untuk membawa konsep fisika dalam kehidupan sehari-hari. Hal tersebut menyebabkan siswa menjadi tidak aktif dan kreatif sehingga pelajaran fisika menjadi membosankan dan menjadi salah satu pelajaran yang sulit dipelajari dan tidak disukai oleh siswa. Akibatnya siswa kurang mampu memahami dan menerapkan konsep fisika dalam kehidupan sehari-hari.

Berdasarkan hasil studi pendahuluan yang dilakukan peneliti di SMA Negeri Unggul, yakni wawancara dengan guru fisika SMA Negeri Unggul pada tanggal 08 November 2014 mengungkapkan bahwa hasil belajar fisika siswa masih rendah. Hasil belajar fisika siswa kelas $\mathrm{X}$ dalam Ujian Akhir Semester Ganjil setiap tahunnya hanya mencapai rata-rata 55, sedangkan Kriteria Ketuntasan Minimal (KKM) yang akan dicapai adalah 75, sehingga dapat dikatakan nilai rata-rata siswa tidak mencapai kriteria yang diharapkan. Kegiatan belajar di kelas saat ini cenderung masih menggunakan pembelajaran konvensional dengan metode yang digunakan guru adalah ceramah, tanya jawab, dan penugasan. Guru yang mengajar dengan model pembelajaran yang kurang menarik dapat menyebabkan siswa menjadi bosan, pasif, dan tidak kreatif. Dengan demikian guru dituntut untuk menggunakan model pembelajaran yang disesuaikan dengan kondisi dan situasi belajar agar tujuan akhir belajar dapat tercapai.

Salah satu alternatif model pembelajaran yang memungkinkan diterapkan adalah model problem based learning (PBL). Model PBL merupakan pendekatan yang efektif untuk pengajaran proses berpikir tingkat tinggi (Trianto, 2010). Berpikir tingkat tinggi adalah kerja keras. Pembelajaran PBL dikembangkan untuk membantu siswa mengembangkan kemampuan berpikir, pemecahan masalah dan keterampilan intelektual, belajar berbagai peran orang dewasa melalui perlibatan mereka dalam pengalaman nyata dan menjadi pebelajar yang otonom dan mandiri.

Penerapan model pembelajaran PBL ini sudah pernah diteliti oleh beberapa peneliti sebelumnya, seperti Kennedy (2008) menerapkan model PBL di SMA N 4 Kisaran pada materi pokok Pemuaian diperoleh nilai rata-rata pretes kelas eksperimen 30,66 setelah diberi perlakuan 
dengan model PBL maka hasil belajar fisika siswa meningkat dengan nilai rata-rata postes 68,66 . Berdasarkan hasil peneliti ini diketahui bahwa ada pengaruh model pembelajaran PBL terhadap hasil belajar siswa.

\section{METODE PENELITIAN}

Penelitian dilaksanakan di SMAN Unggul Subulussalam dengan populasi seluruh siswa kelas X SMAN sebanyak 3 kelas. Pengambilan sampel dilakukan secara cluster random sampling. Dari tiga kelas hanya dua yang dijadikan sampel penelitian. Satu kelas sebagai kelas eksperimen yaitu kelas yang menggunakan model problem based learning dan kelas kontrol yaitu kelas yang menggunakan pembelajaran konvensional. Variabel dalam penelitian ini terdiri dari dua jenis yaitu variabel bebas adalah pembelajaran dengan model problem based learning pada kelas eksperimen dan pembelajaran konvensional pada kelas kontrol dan variable terikat adalah hasil belajar siswa pada materi pokok gerak lurus.

Penelitian ini termasuk jenis penelitian quasi exsperiment dengan desain two group pretes-postes design seperti yang ditunjukkan pada Tabel 1.

Tabel 1. Desain penelitian (two group pretes-postes design)

\begin{tabular}{|l|l|l|l|}
\hline kelas & pretes & $\begin{array}{l}\text { Perlakua } \\
\mathrm{n}\end{array}$ & Postes \\
\hline Eksperimen & $\mathrm{T}_{1}$ & $\mathrm{X}_{1}$ & $\mathrm{~T}_{2}$ \\
\hline kontrol & $\mathrm{T}_{1}$ & $\mathrm{X}_{2}$ & $\mathrm{~T}_{2}$ \\
\hline
\end{tabular}

Keterangan :

$\mathrm{T}_{1}$ : Pretes diberikan kepada kelas eksperimen dan kelas kontrol sebelum diberikan perlakuan.

$\mathrm{T}_{2} \quad$ : Postes diberikan setelah diberika perlakuan kepada kelas eksperimen dan kelas kontrol.

$\mathrm{X}_{1}$ : Pembelajaran dengan menerapkan model problem based learning.

$\mathrm{X}_{2} \quad$ : Pembelajaran menerapkan konvensional.
Instrumen yang digunakan dalam penelitian ini adalah tes hasil belajar siswa berjumlah 10 soal dalam bentuk essay test dan diberikan sebanyak 2 kali yaitu pretes dan postes.

Tes hasil belajar terlebih dahulu distandarisasi dengan menggunakan uji validitas oleh dua dosen dan satu uru sesuai pakar ahlinya. Setelah data pretes diperoleh, dilakukan analisis data dengan uji normalitas dengan uji Lilliefors dan uji homogenitas dengan uji kesamaan varians. Setelah itu dilakukan pengujian hipotesis uji $\mathrm{t}$ untuk mengetahui kemampuan awal siswa pada kedua kelompok sampel, dalam hal ini kemampuan awal kedua sampel tersebut harus sama. Selanjutnya kedua sampel diberikan perlakuan yang berbeda dengan materi yang sama yaitu menggunakan model problem based learning pada kelas eksperimen dan pembelajaran konvensional pada kelas kontrol. Perbedaan hasil akhir diperoleh dengan dilakukan postes menggunakan uji $\mathrm{t}$ untuk mengetahui pengaruh model problem based learning terhadap hasil belajar siswa.

\section{HASIL DAN PEMBAHASAN Hasil penelitian}

Awal tahap penelitian, kedua kelas sampel yaitu kelas eksperimen dan kelas kontrol diberikan pretes sebagai syarat awal penelitian yang bertujuan untuk melihat kemampuan awal belajar siswa pada kedua kelas tersebut. Setelah dilakukan pretes, pada kelas eksperimen diperoleh nilai rata rata 43,81 dan pada kelas kontrol diperoleh nilai rata-rata 44,05.

Setelah memperoleh data hasil pretes siswa dari kelas eksperimen dan kelas kontol, maka dilakukan pengujian analisis data dengan menggunakan uji kesamaaan rata - rata pretes dimana syaratnya data harus berdistribusi normal dan homogen. Hasil uji normalitas data pretes kelas eksperimen dan kelas kontrol ditunjukkan pada Tabel 2.

Tabel 2. Hasil Uji Normalitas Pretes dan Postes

\begin{tabular}{|l|l|l|l|}
\hline Kelas & Data pretes & Data postes & Kesim \\
\hline
\end{tabular}




\begin{tabular}{|l|l|l|l|l|l|}
\hline \multirow{2}{*}{} & \multicolumn{2}{|l|}{} & \multicolumn{2}{|l|}{} & pulan \\
\cline { 2 - 6 } & $\mathrm{L}_{\text {hit }}$ & $\mathrm{L}_{\text {tab }}$ & $\mathrm{L}_{\text {hit }}$ & $\mathrm{L}_{\text {tab }}$ & \\
\hline $\begin{array}{l}\text { Eksperi- } \\
\text { men }\end{array}$ & 0,07 & 0,15 & 0,07 & 0,15 & $\begin{array}{l}\text { Nor- } \\
\text { mal }\end{array}$ \\
\hline kontrol & 0,08 & 0,15 & 0,14 & 0,15 & $\begin{array}{l}\text { Nor- } \\
\text { mal }\end{array}$ \\
\hline
\end{tabular}

Berdasarkan Tabel 2 setelah dilakukan uji Lilliefors data pretes dan postes kedua kelas dapat dikatakan normal dengan nilai $\mathrm{L}_{\text {hit }}<\mathrm{L}_{\text {tab. }}$ Hasil uji homogenitas data pretes - postes pada kelas eksperimen dan kelas kontrol ditunjukkan pada Tabel 3.

Tabel 3. Uji Homoenitas Pretes dan Postes

\begin{tabular}{|c|c|c|c|}
\hline Data & $\mathrm{F}_{\mathrm{tab}}$ & $\mathrm{F}_{\text {hit }}$ & kesimpulan \\
\hline $\begin{array}{l}\text { Pretes kelas } \\
\text { eksperimen }\end{array}$ & \multirow{2}{*}{1,74} & \multirow{2}{*}{1,57} & \multirow{2}{*}{ homogen } \\
\hline $\begin{array}{ll}\text { Pretes } & \text { kelas } \\
\text { kontrol } & \\
\end{array}$ & & & \\
\hline $\begin{array}{l}\text { Postes kelas } \\
\text { eksperimen }\end{array}$ & \multirow{2}{*}{1,74} & \multirow{2}{*}{1,05} & \multirow{2}{*}{ homogen } \\
\hline $\begin{array}{ll}\text { Postes } & \text { kelas } \\
\text { kontrol } & \\
\end{array}$ & & & \\
\hline
\end{tabular}

Berdasarkan Tabel 3 setelah dilakukan pengujian dengan uji $\mathrm{F}$ maka pada data pretes dan postes kedua kelas dapat dkatakan homogen dengan $\mathrm{F}_{\text {hit }}<\mathrm{F}_{\text {tab. }}$. Selanjutnya hasil uji hipotesis postes pada kedua kelas dapat dilihat pada Tabel 4.

Tabel 4. Hasil Uji Hipotesis Data Postes

\begin{tabular}{|l|l|l|l|l|}
\hline Data & $\begin{array}{l}\text { Nilai } \\
\text { rata- } \\
\text { rata }\end{array}$ & thit & $\mathrm{t}_{\text {tab }}$ & $\begin{array}{l}\text { Kesim } \\
\text { pulan }\end{array}$ \\
\hline Eksperimen & 80,05 & 4,6 & 1,7 & $\begin{array}{l}\mathrm{H}_{\mathrm{a}} \text { di- } \\
\text { terima }\end{array}$ \\
\hline Kontrol & 68,81 & 4,6 & \multicolumn{3}{|c}{} \\
\hline
\end{tabular}

Berdasarkan Tabel 4 kelas eksperimen yang diajarkan dengan model PBL memperoleh nilai rata-rata hasil belajar adalah 80,05 dan kelas kontrol yang diajarkan dengan model konvensional memperoleh hasil belajar dengan rata-rata 68,81. Data di atas menunjukkan bahwa $\mathbf{t}_{\text {hitung }}>\mathbf{t}_{\text {tabel }}(4,550>1,668)$, sehingga dapat disimpulkan bahwa ada pengaruh model problem based learning (PBL) terhadap hasil belajar siswa pada materi gerak lurus di kelas X SMAN Unggul Subulussalam tahun 2015.
Penilaian aktivitas siswa harus menjadi bagian dari hasil belajar dan harus tampak dalam proses belajar yang dicapai oleh siswa. Hasil penilaian aktivitas siswa pada kelas eksperimen dapat dilihat pada Tabel 5.

Tabel 5. Peningkatan Aktivitas Pada Kelas Eksperimen

\begin{tabular}{|l|l|l|l|}
\hline pertemuan & I & II & III \\
\hline Rata-rata & $69,39 \%$ & $72,42 \%$ & $74,23 \%$ \\
\hline Kategori & aktif & aktif & aktif \\
\hline
\end{tabular}

Berdasarkan Tabel 5 dapat dilihat bahwa terjadi peningkatan aktivitas belajar siswa pada kelas eksperimen selama proses pembelajaran menggunakan model problem based learning.

\section{Pembahasan}

Hasil penelitian menunjukkan bahwa ada pengaruh yang signifikan menggunakan model pembelajaran problem based learning terhadap hasil belajar siswa pada materi pokok gerak lurus dikelas $\mathrm{X}$ semester I SMAN Unggul Subulussalam. Hal ini diperkuat dengan perolehan nilai rata-rata pretes siswa dikelas eksperimen sebesar 43,81 nilai rata-rata postes sebesar 80,05. Sedangkan di kelas kontrol diperoleh nilai rata-rata pretes siswa sebesar 44,05 dan nilai rata-rata postes sebesar 68,81 , kemudian aktivitas siswa pada kelas eksperimen mengalami peningkatan yaitu $74,24 \%$ dengan kategori aktif. Data mengenai aktivitas siswa, menunjukkan bahwa terjadi peningkatan aktivitas siswa secara perlahan. Hal ini disebabkan karena pada saat proses belajar mengajar dengan menggunakan model pembelajaran berbasis masalah siswa dilibatkan secara aktif dalam proses pembelajaran. Siswa dituntut untuk mengembangkan kemampuan berpikir ketika disajikan suatu permasalahan dan adanya interaksi yang terjadi antar siswa maupun antara siswa dengan guru yang melatih kemampuan berkomunikasi, seperti yang terlihat ketika diskusi di kelas terjadi interaksi tanya jawab dan siswa bebas mengeluarkan pendapatnya masing-masing. Pernyataan peneliti sejalan dengan pendapat 
Arends (2008 : 52), pembelajaran berbasis masalah merupakan suatu pendekatan pembelajaran di mana siswa mengerjakan permasalahan yang otentik dengan maksud untuk menyusun pengetahuan mereka sendiri, mengembangkan inkuiri dan keterampilan berpikir tingkat lebih tinggi dan mengembangkan kemandirian dan percaya diri. Model pembelajaran ini juga mengacu pada model pembelajaran yang lain, seperti "pembelajaran berdasarkan proyek (project-based instruction)", "pembelajaran berdasarkan pengalaman (experience-based instruction)", "belajar otentik (authentic learning)" dan "pembelajaran bermakna (anchored instruction)".

Beberapa hasil penelitian terdahulu yang menggunakan model problem based learning, diantaranya Tamba (2014:147) diperoleh nilai rata-rata pretes kelas eksperimen sebesar 30.5 dan nilai rata-rata postes sebesar 68.9. Pada kelas kontrol diperoleh nilai rata-rata pretes siswa sebesar 29,3 dan nilai rata-rata postes sebesar 60,4. Aktivitas siswa selama mengikuti pembelajaran dengan menggunakan modelproblem based learning diperoleh skor rata-rata aktivitas siswa mencapai $61,43 \%$ dengan kategori aktif. Peneliti lainnya adalah Utrifani (2014:9) diperoleh nilai rata-rata pretes kelas eksperimen sebesar 23,91 dan nilai rata-rata postes sebesar 74,97. Pada kelas kontrol diperoleh nilai rata-rata pretes sebesar 21,87 dan nilai rata-rata postes sebesar 69,87. Aktivitas siswa selama mengikuti pembelajaran menggunakan model problem based learning diperoleh skor rata-rata aktivitas siswa mencapai $67,12 \%$ dengan kategori aktif. Berdasarkan hasil penelitian, terbukti bahwa model pembelajaran problem based learning $(P B L)$ dapat meningkatkan hasil belajar siswa pada materi pokok gerak lurus. Disamping itu, model problem based learning $(P B L)$ yang digunakan dalam penelitian sesuai dengan teori konstruktivisme yakni siswa memiliki pengetahuan, mengembangkan keterampilan berpikir, keterampilan mengatasi masalah dan keterampilan intelektualnya serta menjadi pelajar yang mandiri dan otonom.

Kelebihan yang dapat diberikan dengan menggunakan model pembelajaran problem based learning adalah meningkatkan kemampuan siswa dalam pemecahan masalah dan menjadi pebelajar yang otonom dan mandiri. Langkahlangkah pembelajaran pada model pembelajaran problem based learning mendorong siswa untuk lebih aktif di dalam kelas. Misalnya pada saat mengerjakan LKS, siswa dibagi ke dalam kelompok yang hanya beranggotakan 6 sampai 7 orang siswa, mengerjakan LKS selama 30 menit, kemudian mempresentasikan hasil diskusi kepada teman-teman yang lain. Hal ini mendorong siswa untuk lebih berpartisipasi dalam kerja kelompoknya. Siswa juga tertarik dan aktif saat berdiskusi dan mengeluarkan pendapat yang berbeda saat diadakan diskusi antar kelompok.

Penggunaan model pembelajaran berbasis masalah dapat meningkatkan hasil belajar dan aktivitas belajar siswa, tetapi selama pembelajaran berlangsung masih ada kendala yang dihadapi peneliti yaitu pada fase ke-3 dalam sintaks model Problem Based Learning dimana ketika peneliti menyajikan fenomena atau demonstrasi atau suatu cerita yang bisa memunculkan masalah yang akan dipecahkan saat proses pembelajaran berlangsung. Kesulitan yang dihadapi peneliti yaitu kurang terbiasanya siswa melakukan penyelidikan individu dan kelompok sehingga peneliti memerlukan banyak waktu dalam membimbing pelaksanaan penyelidikan.

Selain itu, hasil penilaian aktivitas juga belum dapat memberikan gambaran meningkatkan hasil belajar siswa seperti yang diharapkan, dalam hal ini kelemahan yang terjadi dapat disebabkan oleh penjelasan peneliti yang kurang memadai kepada observer dan banyaknya siswa dalam setiap kelompok yang harus diamati observer . 


\section{KESIMPULAN DAN SARAN \\ Kesimpulan}

Berdasarkan hasil analisis uji statistik maka disimpulkan bahwa terdapat pengaruh model Problem Based Learning terhadap hasil belajar siswa pada materi pokok gerak lurus di kelas $\mathrm{X}$ SMAN Unggul Subulussalam. Hasil observasi aktivitas belajar siswa setelah diberikan perlakuan model problem based learning dalam tiga pertemuan juga mengalami peningkatan dan dalam kategori aktif.

\section{Saran}

Adapun yang menjadi kelebihan model pembelajaran problem based learning ini adalah meningkatnya tingkat berfikir siswa untuk memecahkan masalah yang diajukan. Sedangkan kelemahannya adalah keterbatasan alokasi waktu yang membuat model pembelajaran ini kurang efektif untuk dilaksanakan. Disarankan bagi peneliti selanjutnya hendaknya dapat mengatur waktu dari setiap sintaks model PBL.

\section{DAFTAR PUSTAKA}

Arends, R.I.,(2008), Learning To Teach,Edisi Ketujuh. Diterjemahkan oleh Soetjipto,Prajitno. PustakaPelajar : Yogyakarta

Kennedy,(2009), Perbedaan Hasil belajar Siswa Menggunakan Model Pembelajaran Berbasis Masalah (Problem Based Learning) dengan Konvensional pada Materi Pokok Pemuaian di SMA Negeri 4 Kisaran T.A. 2008/2009. Skripsi. Medan : FMIPA Unimed

Rusman,(2012), Model-Model Pembelajaran. Raja Grafindo Persada : Jakarta

Sudjana,(2012), Metode Statistika. Tarsito : Bandung

Tamba, P.,(2014), Pengaruh Model Pembelajaran Problem Based Learning untuk Meningkatkan Hasil Belajar Siswa Pada Materi Pokok Cahaya di Kelas VIII SMP Swasta
Assisi Medan T.A 2013/2014. Jurnal Inpafi vol.3,No.1,pp.147-154

Trianto,(2010), Mendesain Model Pembelajaran Inovatif-Progresif. Kencana : Jakarta

Utrifani, A.,(2014), Pengaruh Model Pembelajaran Problem Based Learning Terhadap hasil Belajar Siswa Pada Materi Pokok Kinematika Gerak Lurus Kelas X SMA Negeri 14 Medan T.P 2013/2014. Jurnal Inpafi vol.2,No.2,pp.9-16 
